\title{
Acoustic Performance of Metallic Foams
}

\author{
A. Arjunan ${ }^{1}$, A. Baroutaji ${ }^{*}$, A. S. Praveen ${ }^{2}$, A. G. Olabi ${ }^{3,4}$ and C. J. Wang ${ }^{5}$ \\ ${ }^{1}$ School of Engineering, University of Wolverhampton, Telford Innovation Campus, TF2 9NT, UK \\ ${ }^{2}$ Department of Mechanical Engineering, Vel Tech Rangarajan Dr. Sagunthala R\&D Institute of Science and \\ Technology, Tamil Nadu, India \\ ${ }^{3}$ Department of Sustainable and Renewable Energy Engineering, University of Sharjah, P.O. Box 27272, Sharjah, \\ UAE \\ ${ }^{4}$ School of Engineering and Applied Science, Aston University, Aston Triangle, Birmingham B4 7ET, UK \\ ${ }^{5}$ Deptartment of Engineering and Design, University of Sussex, Brighton BN1 9RH, UK
}

\begin{abstract}
Metallic foams are among the most promising class of materials due to their unique mechanical properties combining low mass with high stiffness, excellent energy absorption, and vibroacoustic damping. Consequently, noise control using methodically engineered metallic foams has received increased attention from both industrial and scientific community. Accordingly, this paper aims to present the mechanism of sound absorption along with the experimental and theoretical procedure that can be used to classify metallic foams. Additionally, the influence of design parameters on the resulting sound absorption coefficient of closed and opencell metallic foams are explored. While aluminium foams used to dominate the literature when it comes to acoustics, recent studies have reported Nickel-Inconel superalloy and Copper foams as having superior sound absorption coefficients.
\end{abstract}

Keywords: Metallic Foams; Porous Materials; Open and Closed Cell; Sound Absorption Coefficient; Prediction Models; Impedance Tube; Aluminium; Nickel-Inconel; Copper

\footnotetext{
* Corresponding author. Address: School of Engineering, Faculty of Science and Engineering, University of Wolverhampton, Telford Campus, Shifnal Road, Priorslee, Telford, TF2 9NT, UK. Tel.: +44 (0)1902 322981; fax: +44 (0)1902 323843.

E-mail address: A.Baroutaji@wlv.ac.uk (Ahmad Baroutaji).
} 


\section{Introduction}

Lightweight structures that combine high structural stiffness, energy absorption [1-3] and acoustic performance [4-8] are of interest to automotive, aerospace and the construction sectors. Automotive floor panels [9] and aerospace bulkheads [10] are examples of mechanical structures where the secondary function extends to providing adequate acoustic comfort. Consequently, metallic foam materials are investigated as a potential contender in this aspect due to their favourable mechanical and vibroacoustic properties [11]. Commercially available metallic foam materials such as the ones shown in Figure 1 are known to have low mass and high stiffness properties $[12,13]$. Furthermore, the porous structure featured by these foams have been found to exhibit enhanced acoustic absorption, higher damping, and eigenmode frequencies compared to their solid counterparts $[14,15]$.

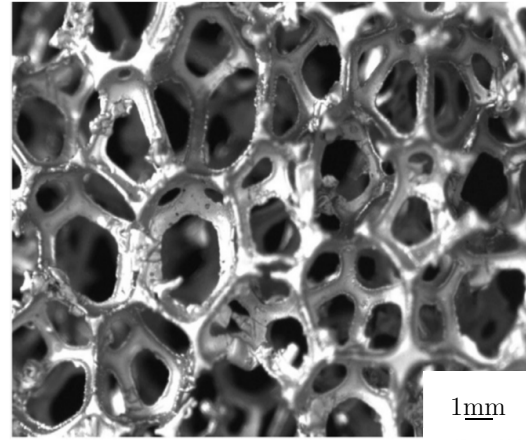

(a)

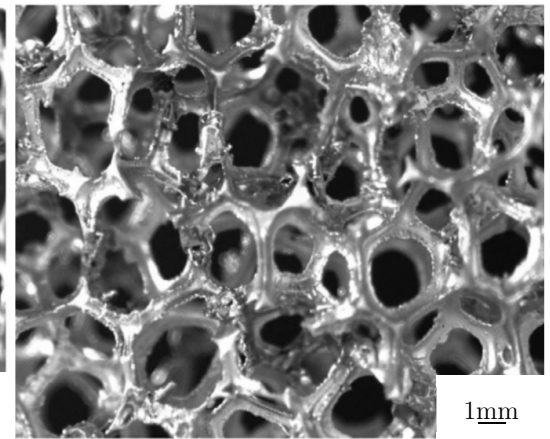

(b)

Figure 1. Structure of a typical metallic foam where the material (a) is Nickel and (b) Copper [16].

Acoustic absorption refers to the energy of an incident sound wave that is neither reflected nor transmitted by the material. Instead, the soundwave is absorbed within the material through energy conversion as shown in Figure 2. This mechanism of acoustic absorption within the material can be due to some or all of the following five mechanisms [17]:

i. Viscous losses.

ii. Thermal-elastic damping.

iii. Resonance within the pore cavities.

$i v$. Vortex shedding at sharp edges.

$v$. Direct mechanical damping in the material itself.

Comparing the influence of the above five mechanisms, the contribution of direct mechanical damping on the acoustic absorption of metallic foams is relatively small due to the high stiffness exhibited by the metallic struts within the foam. In addition, the influence of vortex shedding is also negligible in the absence of mean flow [18]. Considering these two aspects, the acoustic absorption in metallic foams can be primarily attributed to viscous losses, thermal-elastic damping, and resonance within the pore cavities. 


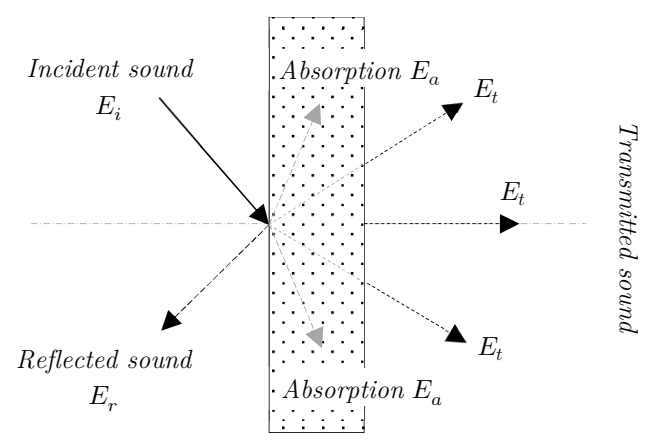

Figure 2. Acoustic absorption along the cross-section of a porous material.

Out of all different metallic foams studied [19-26], Aluminium (Al) foam has the highest literature [27-31] relating to acoustic performance due to its application in aerospace and automotive industries. Studies conducted by Wang et al. [32] and Itoh et al. [33] on close-celled $\mathrm{Al}$ foams showed that the optimum pore size for acoustic absorption is around $0.1 \mathrm{~mm}$. However, the influence of structural parameters such as the foam thickness, strut width or volumetric open porosity were not considered.

According to $\mathrm{Lu}$ et al. $[17,34]$ the acoustic absorption of metallic foams with partially open pores increased when the pore size decreased. Furthermore, the peak sound absorption coefficient $(\alpha)$ of such foams were observed to be 0.8 within a frequency range 0.8 to $2 \mathrm{kHz}$. On the other hand, for closed-cell foams, a pore size between 2 and $4 \mathrm{~mm}$ was reported most effective. Overall, the studies showed that $\alpha$ was closely linked to the relative density and the type of porosity (open, semi-open or closed) that the metallic foam featured.

The inconsistency in the use of pore size to characterise the acoustic absorption of metallic foams lead Han et al. [35] to propose the use of airflow resistance as an alternative criterion. Accordingly, best sound absorption was at an airflow resistance between 0.04 and 0.045 rayls $/ \mathrm{m}$, independent of the type of porosity. Nevertheless, the use of airflow resistance is still not widely prevalent with 'porosity type' being repeatedly quoted in scientific literature.

\section{Measurement of sound absorption in metallic foams}

\subsection{Parameters associated acoustic pressure}

The sound absorption coefficient $(\alpha)$ is the standard measurement used to characterise a material's effectiveness in absorbing acoustic energy. Before introducing the relationships associated with $\alpha$, a certain understanding of related parameters is necessary when it comes to material acoustics. A sound wave often starts as an acoustic disturbance as a result of vibration in an elastic medium that can be represented using Eqn. (1):

$$
v=f \lambda
$$

Where,

$v$ is the velocity 
$\lambda$ is the wavelength

$f$ is the frequency

From a human hearing perspective, the frequency range of importance when it comes to acoustics is from $20 \mathrm{~Hz}$ to $20 \mathrm{kHz}$. The acoustic pressure has an order of $10^{6}$ in Pascals $(\mathrm{Pa})$, therefore the standard practice normally adopts a logarithmic scale using decibels $(\mathrm{dB})$. The decibel scale for Sound Pressure Level (SPL) is defined using Eqn. (2):

$$
S P L=10 \log _{10}\left(\frac{P_{r m s}}{P_{r e f}}\right)^{2}=20 \log _{10}\left(\frac{P_{r m s}}{P_{r e f}}\right)
$$

Where,

$P_{r m s}$ is the mean-square sound pressure

$P_{r e f}$ is the reference pressure

Accordingly, the sound absorption coefficient $(\alpha)$ is the representation of the acoustic energy that is absorbed after being incident on a material's surface. $\alpha$ at normal incidence is measured using the impedance tube experimental setup. Despite being widely accepted $\alpha$ does not conform to the definition of 'material property' as it varies with material thickness, fixing method and enclosed cavity (air gap). Considering this, the acoustic performance of a homogenous material can be more conveniently characterised using the material properties Characteristic impedance $(\tilde{Z})$ and Propagation constant $(\widetilde{m})[36]$.

The characteristic impedance $(\tilde{Z})$ is the ratio of acoustic pressure to air particle velocity at the entrance surface of an acoustic plane perpendicular to the surface. For the propagation constant $(\widetilde{m})$, also known as the complex wave number [37], the real part defines the sound energy attenuated across the material, whereas the imaginary part measures the sonic velocity.

For metallic foams, it is still challenging to quantify a thickness independent material property due to the complex nature of the pores. Consequently, in subsequent sections, the sound absorption of metallic foams is discussed with regards to the pore type, relative density and geometrical $[38,39]$. This was the chosen approach to allow readers to make cross reference with existing literature in the area.

\subsection{Impedance tube experiment}

\subsubsection{Measurement of Sound absorption coefficient $(\alpha)$}

For metallic foams, the acoustic properties are measured by determining the input impedance of a specimen using an impedance tube $[7,40,41]$ shown in Figure 3. An acoustic waveform is generated at one end and the metallic foam placed at the other end of the tube. The end termination features a movable piston allowing to create an arbitrary air depth at the rear of the metallic foam if necessary. 


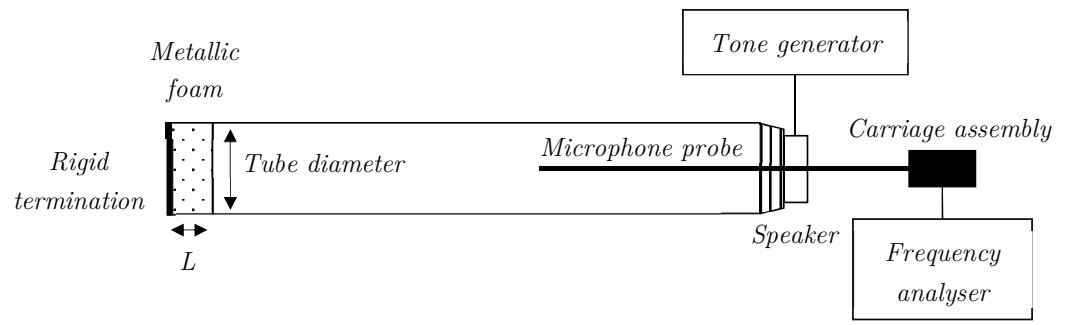

Figure 3. Impedance tube standing wave method to measure the sound absorption coefficient $(\alpha)$.

The sound source is a sine wave played through the loudspeaker initiated by a tone generator within a frequency range of 10 to $20 \mathrm{kHz}$. The microphone is then moved within the impedance tube to obtain the maximum and minimum SPL. The acoustic response recorded by the microphone is then amplified and analysed through a frequency analyser. The resultant standing wave pattern in the tube is a result of partial reflection of the sound wave by the metallic foam [42]. Then the normal incident sound absorption coefficient $(\alpha)$ can then be calculated using Eqn. (3):

$$
\alpha=1-\left(\frac{\frac{P_{\max }}{P_{\min }}-1}{\frac{P_{\max }}{P_{\min }}+1}\right)^{2}
$$

Where,

$$
P_{\min } \text { and } P_{\max } \text { represents the minimum and maximum SPL of the standing wave. }
$$

Accordingly, $\alpha$ represents the incident sound energy that is absorbed by the impedance tube including the metallic foam sample. As long as the absorption of the cavity walls remain minimal, the measured response can be primarily attributed to the acoustic performance of metallic foam sample.

\subsubsection{Characteristic impedance $(\tilde{Z})$ and propagation constant $(\widetilde{m})$}

A modification of the test setup from Figure 3 through the addition of a secondary air cavity [43] is required to measure $\tilde{Z}$ and $\widetilde{m}$. Consequently, for a metallic foam of thickness $L$ and an air cavity of depth $d$ between the foam and the base of the tube; the $\tilde{Z}$ and $\widetilde{m}$ can be related using Eqn. (4) [40]:

$$
\tilde{Z}_{s}=\tilde{Z} \frac{\tilde{Z}_{r} \cosh (\widetilde{m} L)+\tilde{Z} \sinh (\widetilde{m} L)}{\tilde{Z}_{r} \sinh (\widetilde{m} L)+\tilde{Z} \cosh (\widetilde{m} L)}
$$

Where, $\tilde{Z}_{s}$ is the surface impedance of the metallic foam at the front and $\tilde{Z}_{r}$ impedance at the rear. The measurement of $\tilde{Z}_{s}$ can follow a similar procedure to that of $\alpha, \tilde{Z}_{r}$ of a closed tube with length $d$ are related using Eqn. (5):

$$
\tilde{Z}_{r}=-\left(\rho_{0} c_{0}\right) i \cot \left(\frac{\omega d}{c_{0}}\right)
$$


Where,

$$
\begin{aligned}
& \rho_{0}=1.2 \mathrm{~kg} / \mathrm{m}^{3} \text { (density of air) } \\
& c_{0}=343 \mathrm{~m} / \mathrm{s} \text { (sonic velocity) }
\end{aligned}
$$

There are two unknowns here $(\tilde{Z})$ and $(\widetilde{m})$ requiring two independent measurements on the same specimen. If the measured data is arranged such that, the subscript 1 and 2 denotes depth $d_{1}$ and $d_{2}$, then Eqn. (4) and (5) can be deduced to Eqn. (6) and (7):

$$
\tilde{Z}= \pm\left\{\frac{\tilde{Z}_{s 1} \tilde{Z}_{s 2}\left(\tilde{Z}_{r 1}-\tilde{Z}_{r 2}\right)-\tilde{Z}_{r 1} \tilde{Z}_{r 2}\left(\tilde{Z}_{s 1}-\tilde{Z}_{s 2}\right)}{\left(\tilde{Z}_{r 1}-\tilde{Z}_{r 2}\right)-\left(\tilde{Z}_{s 1}-\tilde{Z}_{s 2}\right)}\right\}^{\frac{1}{2}}
$$

and

$$
\widetilde{m}=-\frac{1}{2 L} \ln \left(\frac{\tilde{Z}_{s 1}-\tilde{Z}}{\tilde{Z}_{s 1}+\tilde{Z}} \frac{\tilde{Z}_{r 1}+\tilde{Z}}{\tilde{Z}_{r 1}-\tilde{Z}}\right)
$$

After calculating $(\tilde{Z})$ and $(\widetilde{m})$ using Eqn. (6) and (7), the sound absorption coefficient $(\alpha)$ of a metallic foam of arbitrary thickness and air cavity can be calculated using Eqn. (8):

$$
\alpha=1-\left|\frac{\tilde{Z}_{s}-\rho_{0} c_{0}}{\tilde{Z}_{s}+\rho_{0} c_{0}}\right|^{2}
$$

\section{Mechanism of acoustic absorption in metallic foams}

\subsection{Principle of acoustic energy conversion}

The mechanism of sound absorption in metallic foams are comparable despite the differences in mechanical properties of the bulk material. Consequently, the acoustic energy can be represented using Eqn. (9):

$$
E_{i}=E_{r}+E_{a}+E_{t}
$$

Where,

$E_{i}, E_{r}, E_{a}$, and $E_{t}$ are the incident, reflected, absorbed and transmitted acoustic energy respectively.

Despite the existence of five broad mechanisms in general acoustic terms as discussed in Section 1, the dissipation of acoustic energy in metallic foams can be primarily classified into three attenuation mechanisms [44-46] as shown in Figure 4.

The viscous losses happen when the sound pressure pumps fluid (air) in and out of porous foam cavities. When the longitudinal acoustic waves penetrating the foam pores, the fluid within the pores get compressed and released, resulting in the consumption of acoustic energy in the process. In thermal -elastic damping mechanism, the fluid within the foam cavities vibrate and rub 
against the pore walls resulting in acoustic energy being converted into heat energy. In the final absorption mechanism termed as resonance, energy conversion takes places due to resonance within the pore cavities of the metallic foam.
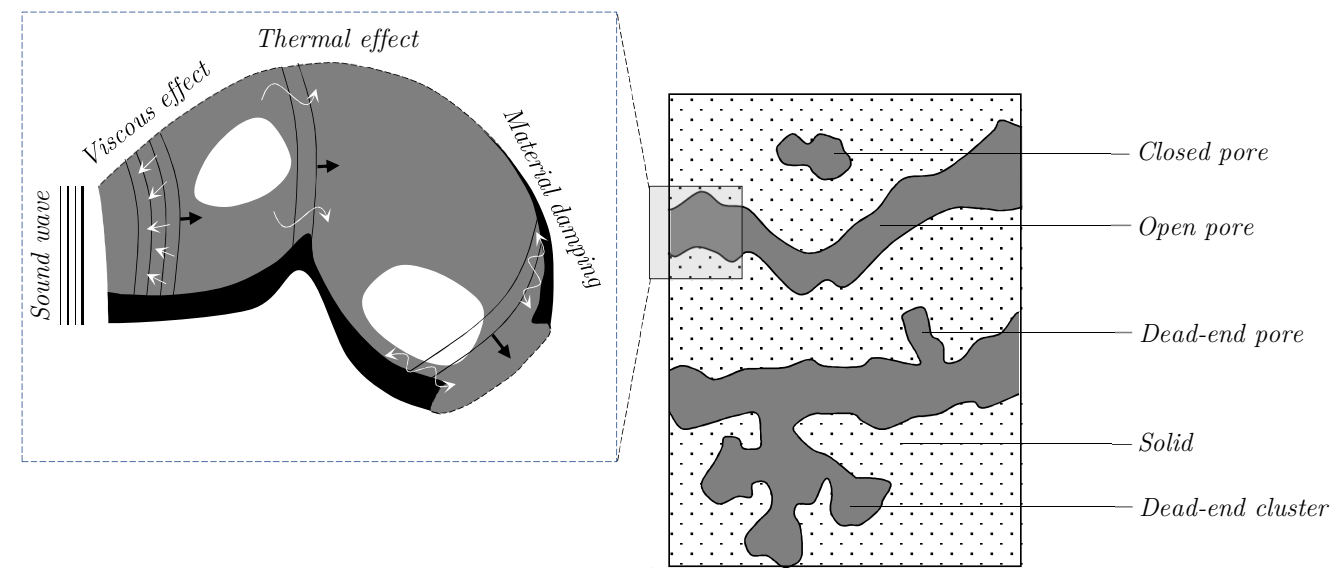

Figure 4. Energy absorption mechanism and pore types in metallic foams [44,47].

Accordingly, an acoustically efficient metallic foam for sound absorption must feature a considerable number of foam cavities that are adequately sized, interconnected and extended throughout the material thickness. A representative example of the type of porosity that contribute to the three aspect of acoustic energy loss can be identified from Figure 4.

\subsection{Prediction of acoustic absorption in metallic foams}

Oliva and Hongisto [48] carried out a review of the accuracy of the acoustic absorption prediction models for porous materials. Among which two approaches can be adopted to develop prediction models for the acoustic absorption of metallic foams. The first approach is following the Delany and Bazley (DBZ) [49] model where the solution is obtained through curve fitting of experimental data.

The DBZ model is often considered for its simplicity as it calls for only one parameter known as the flow resistivity $(\sigma)$ that required to be experimentally measured. The DBZ model in its most fundamental form to predict the characteristic impedance and propagation constant can be expressed using Eqn. (10) and (11) respectively:

$$
\begin{gathered}
\tilde{Z}=\rho_{0} c_{0}\left[1+0.0571\left(\frac{\rho_{0} f}{\sigma}\right)^{-0.754}-j 0.087\left(\frac{\rho_{0} f}{\sigma}\right)^{-0.732}\right] \\
\widetilde{m}=\frac{\omega}{c_{0}}\left[1+0.0978\left(\frac{\rho_{0} f}{\sigma}\right)^{-0.7}-j 0.189\left(\frac{\rho_{0} f}{\sigma}\right)^{-0.595}\right]
\end{gathered}
$$

Where,

$\sigma$ is the flow resistivity. 
$\omega=2 \pi f$ is the angular frequency.

$f$ is the acoustic frequency.

Using Eqn. (10) and (11), the surface impedance to predict the sound absorption coefficient can be expressed using Eqn. (12):

$$
\tilde{Z}_{s}=\tilde{Z} \operatorname{coth}(i \widetilde{m} L)
$$

Where,

$L$ is the thickness of the metallic foam.

The limitation of the DBZ model is that its accuracy is restricted to a range of $0.01<f / \sigma<$ 1.00. However, notable modifications to this model made by Miki [50] and Komatsu [51] are worth exploring in this aspect. The latest (2018) application of the DBZ model to predict $\alpha$ for metallic foam can be found in the works of Zhai et al. [52] where a reasonable fit with experimental data is reported.

One of the fundamental aspects that is worth considering in DBZ model is the neglection of the thermal effects. To this regard, other models evolved considering the geometry of the pores as a structural frame and the air inside the cavities as fluid. This approach is suitable in the case of metallic foams due to the high stiffness variance that exists between the metallic links (solid) and the adjacent fluid (air). Consequently, these models can consider both the viscous and thermal effects within the metallic foams. Nevertheless, the requirement for a 'correction factor' has been reported when it comes to the overall accuracy of $\alpha$ in metallic foams predicted using these models [53]. Furthermore, the number of parameters that are required in these models are higher [54] as shown in Figure 5, when compared to the single parameter $(\sigma)$ featured in the DBZ model.

One such model that can be adopted to predict the acoustic performance of metallic foams is the Johnson-Champoux-Allard (JCA) model [55]. In addition to flow resistivity $(\sigma)$ proposed by DBZ, JCA requires four new parameters, namely; open porosity $(\phi)$, tortuosity $\left(\alpha_{\infty}\right)$, viscous characteristic length $(\Lambda)$ and the thermal characteristic length $\Lambda^{\prime}$.

Using these new parameters; for a metallic foam with a rigid frame and arbitrary pore geometry, the viscous effect can be represented using the 'effective complex density' $\left(\rho_{e}\right)$ and the thermal effect using the 'dynamic bulk modulus' $\left(K_{e}\right)$ as shown in Eqn. (13) and (14) respectively:

$$
\rho_{e}(\omega)=\frac{\alpha_{\infty} \rho_{0}}{\phi}\left(1+\frac{\sigma \phi}{i \omega \rho_{0} \alpha_{\infty}} \sqrt{1+\frac{4 i \alpha_{\infty}^{2} \eta \rho_{0} \omega}{\sigma^{2} \Lambda^{2} \phi^{2}}}\right)
$$




$$
K_{e}(\omega)=\frac{\gamma P_{0}}{\phi}\left(\gamma-(\gamma-1)\left(1+\frac{8 \eta}{i \Lambda^{\prime 2} N_{p r} \omega \rho_{0}} \sqrt{1+\frac{i \rho_{0} \omega N_{p r} \Lambda^{\prime 2}}{16 \eta}}\right)^{-1}\right)^{-1}
$$

Where,

$\eta$ is the viscosity of air.

$\gamma$ is the ratio of the specific heat capacity.

$N_{p r}$ is the Prandtl number.

$P_{0}$ is the atmospheric pressure.

Consequently, the characteristic impedance and the propagation constant along with the corresponding surface impedance is determined using Eqn. (15) and (16):

$$
\begin{gathered}
\tilde{Z}=\sqrt{K_{e}(\omega) \bullet \rho_{e}(\omega)} \\
\widetilde{m}=\omega \sqrt{\frac{\rho_{e}}{K_{e}}}
\end{gathered}
$$

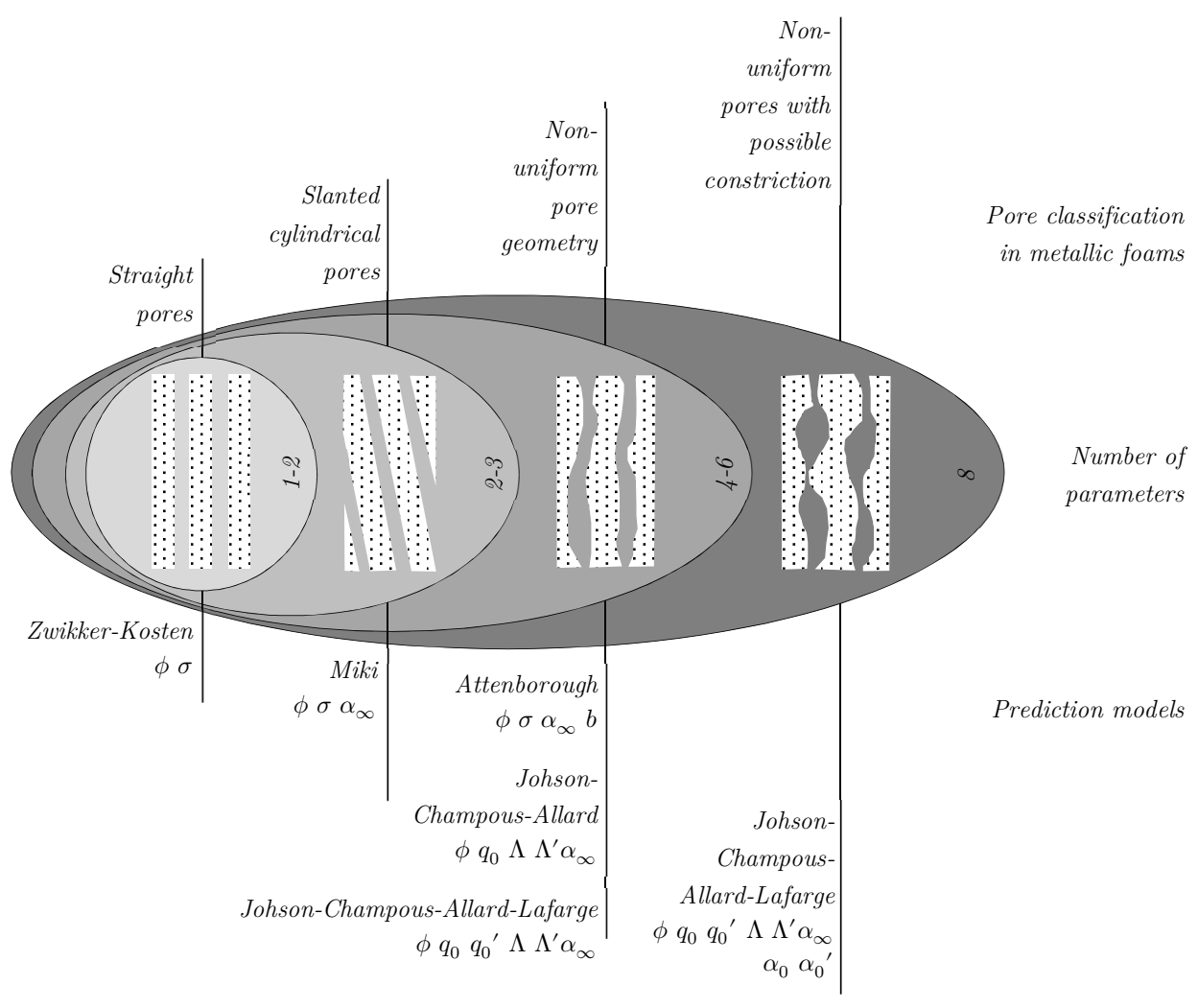

Figure 5. Classification of acoustic prediction models for metallic foams based on the number of parameters $[32,44]$.

Further evolution of the JCA model is the Johnson-Champoux-Allard-Lafarge (JCAL), and Johnson-Champoux-Allard-Pride-Lafarge (JCAPL) models [56]. However, these models bring 
additional parameters as shown in Figure 5; which are challenging to be experimentally or analytically evaluated. Therefore, the DBZ or JCA models generally feature correction factors when it comes to predicting the sound absorption coefficient of metallic foams with complex geometry and boundary conditions. In addition to the models presented in Figure 5, further models utilising the principle of relaxation processes [57] such as the one proposed by Wilson et al. [58] are also available.

\section{Sound absorption coefficient of metallic foams}

\subsection{Closed-cell Aluminium foam}

Aluminium (Al) foams are the most widely studied metallic foam when it comes to acoustic absorption due to their high structural strength in comparison to mass $[59,60]$. Al foams can be generally classified into open and closed-cell according to pore interconnectivity [61]. Closed-cell Al foams [62] are usually favoured for their Sound Reduction Index (R) [63,64] rather than absorption due to their lightweight properties.

The typical structure of a closed-cell commercially available $\mathrm{Al}$ foam is shown in Figure 6. It was first developed by Miyoshi et al. [65] where the manufacturing process involved a batch casting with 1.5 wt.\% Calcium (Ca) used as the thickening agent. Lu et al. [17] carried out experiments on the sound absorption coefficient of $\mathrm{Al}$ foam under variable foam thickness $\left(t_{\text {foam }}\right)$ and relative density $\left(\rho_{r}\right)$. The study was conducted for a frequency range of 200 to $1800 \mathrm{~Hz}$, where the relative density of the foam was represented using Eqn. (17):

$$
\rho_{r}=\frac{\rho_{\text {foam }}}{\rho_{\text {bulk }}}
$$

Where,

$\rho_{\text {foam }}$ and $\rho_{\text {bulk }}$ is the density of foam and the bulk material respectively.

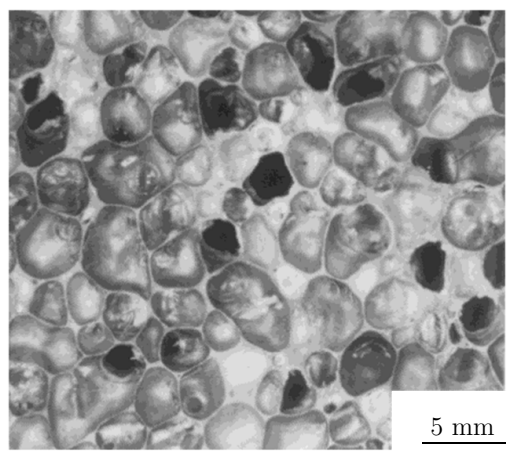

Figure 6. Typical structure of a closed-cell aluminium foam [66].

For closed-cell Al foams, the sound absorption coefficient seems to increase with the decrease in relative density as shown in Figure 7. However, a minimum difference in $\alpha$ was observed above $800 \mathrm{~Hz}$ between foam of relative densities of 0.09 and 0.13 . Furthermore, between a frequency range of 200 to $800 \mathrm{~Hz}$, the influence of relative density on $\alpha$ is minimal. 


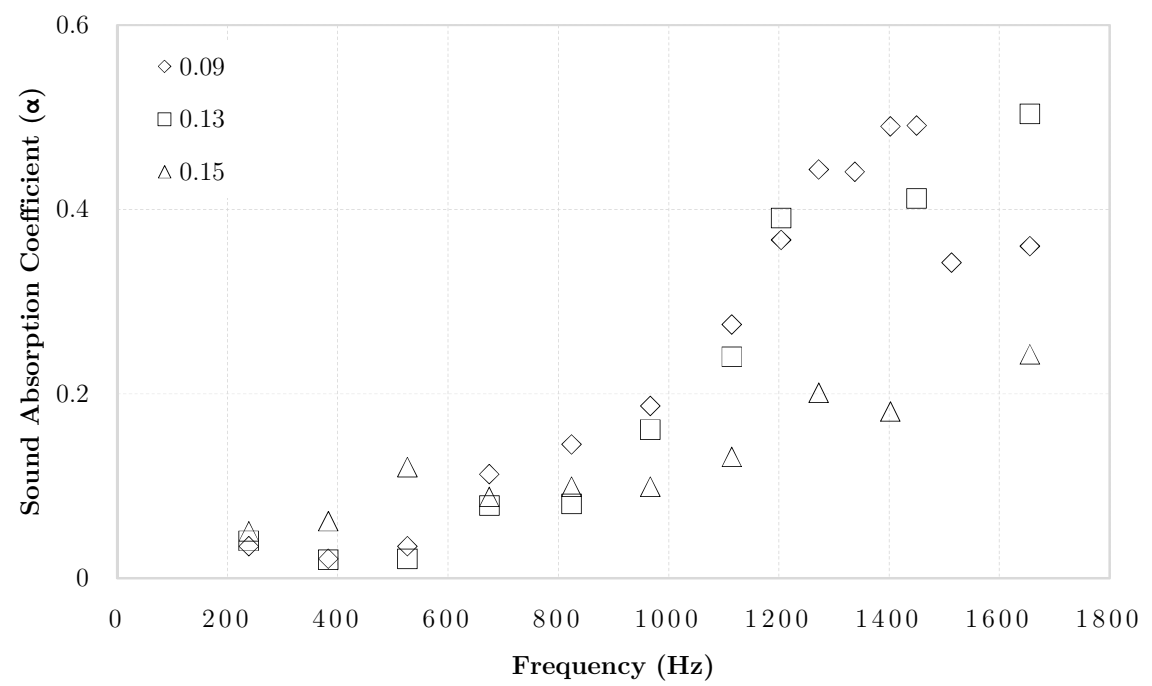

Figure 7. Effect of relative density on the sound absorption coefficient of commercially available aluminium foam of thickness $10 \mathrm{~mm}[17]$.

Sound absorption for cast $\mathrm{Al}$ foams with a relative density 0.09 for various foam thicknesses are shown in Figure 8. Evaluating the results, it is evident that there is an optimum thickness where $\alpha$ is maximised at low frequencies $(400-1200 \mathrm{~Hz})$. For a relative density of 0.09 , the optimum foam thickness that is most effective at low frequency is between 10 and $20 \mathrm{~mm}$ [17]. Nevertheless, it is worth noting that even at an optimum foam thickness, the maximum absorption is limited to 0.6 (rounded). While the lowest absorption was exhibited by the smallest thickness at low frequencies (200-1000 Hz); the highest thickness showed the worse performance between 1200 and $1800 \mathrm{~Hz}$.

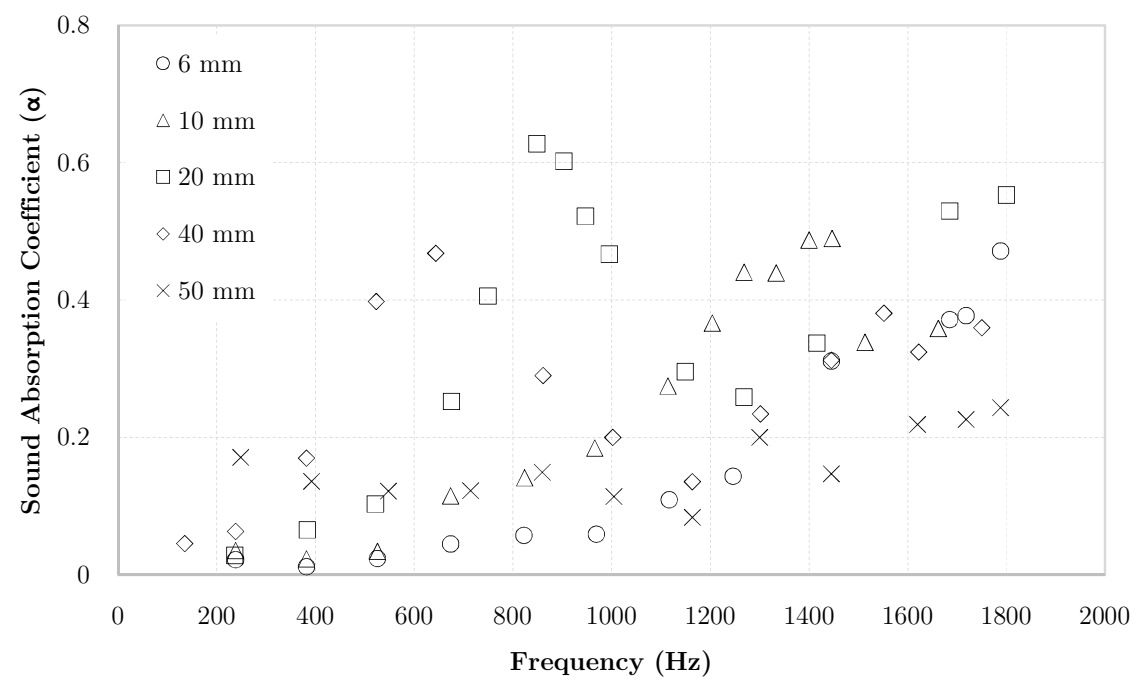

Figure 8. Effect of foam thickness on the sound absorption coefficient of commercially available aluminium foam at a relative density of 0.09 [17]. 


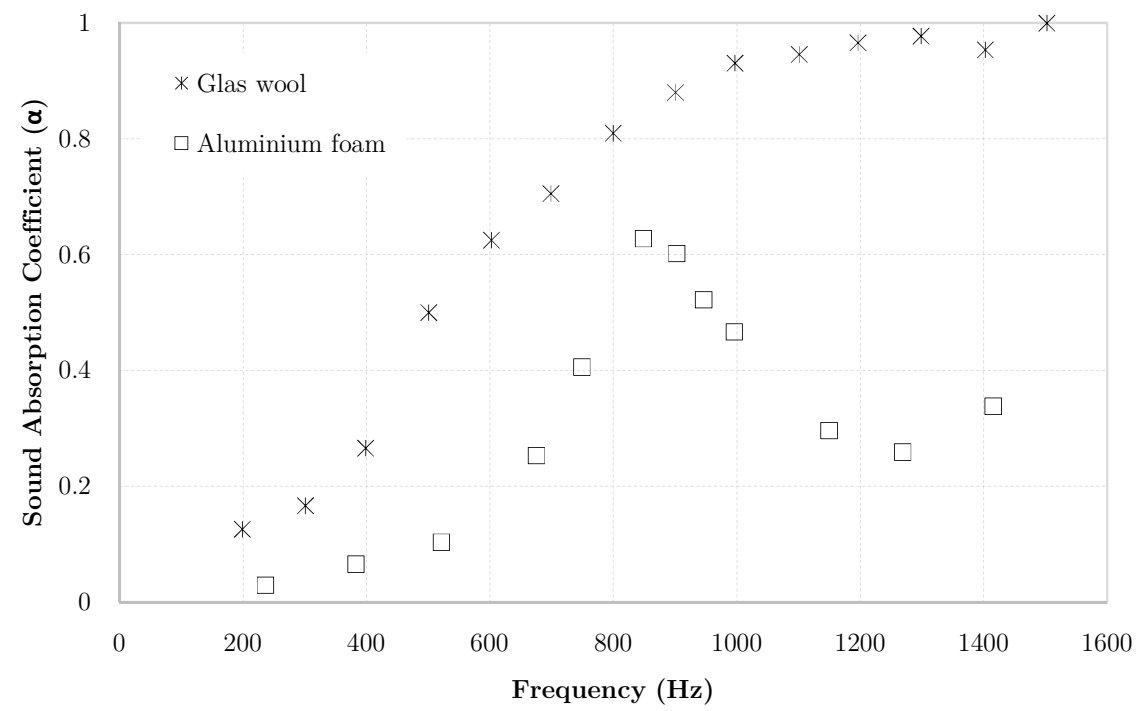

Figure 9. Comparison of sound absorption coefficient between a $50 \mathrm{~mm}$ glass wool and best-performing aluminium foam of thickness $20 \mathrm{~mm}$ and relative density 0.09 [17].

The reduction in acoustic pressure level due to $\alpha$ in (dB) can be expressed using Eqn. (18):

$$
P_{\text {reduction }}(d B)=10 \log _{10}(1-\alpha)
$$

Consequently, an absorption coefficient of 0.5 gives a sound reduction of $3 \mathrm{~dB}$. Comparing $\alpha$ of the best performing closed-cell $\mathrm{Al}$ foam with a traditional sound absorber (50 $\mathrm{mm}$ glass wool) as shown in Figure 9, glass wool outperforms $\mathrm{Al}$ foam where it presents higher $\alpha$ for the whole frequency range. It is interesting to note that the glass wool offers an $\alpha$ of 1 at high frequencies meaning that it can fully absorb the acoustic wave. On the other hand, closed-cell Al foam absorbs some sound requiring further parametric optimisation to make it an effective acoustic absorber. This is despite literature $[65,66]$, calling for sound absorption as one of the primary functions of closed-cell Al foam.

\subsection{Open-cell Aluminium alloy foam}

Open-cell Al foams with the typical structure shown in Figure 10 are considered potential future material to reduce noise pollution $[24,67,68]$. Consequently, there is growing literature on the acoustic performance of open-cell Al foams featuring different design considerations $[61,69]$. Studies by Wang et al. [67] on Al honeycomb structures revealed an optimal pore size $\left(D_{\phi}\right)$ of $0.1 \mathrm{~mm}$ for maximum sound absorption. While conclusions made by Lu et al. [24] suggested that $\alpha$ increased with decreasing $D_{\phi}$. 


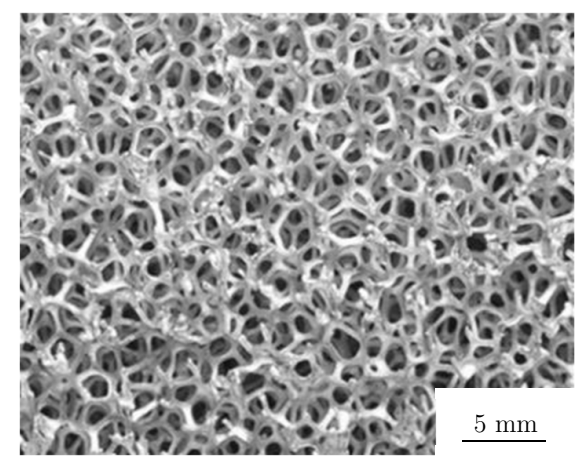

Figure 10. Typical structure of an open-cell aluminium foam [70].

Al foams with pore sizes of 0.5 to $3.5 \mathrm{~mm}$ were studied by Han et al. [68] and found that small pore size while large foam thickness is advantageous for sound absorption. Furthermore, the inclusion of an air gap between the sample and backplate was also suggested as a potential strategy to improve the sound absorption in open-cell metallic foams.

A typical open-cell Al foam made of commercial aluminium have alloying elements as shown in Table 1. In addition, soluble $\mathrm{NaCl}$ (sodium chloride) particles are used as fabricating element to create open porosity. Once the casting process is complete, the $\mathrm{NaCl}$ particles are removed to obtain the porous foam with a representative structure as shown in Figure 10. The porosity of the resulting foam depends on the particle size of $\mathrm{NaCl}$. The samples can then be machined to the required size depending upon the application.

Table 1. Chemical composition of a typical open-cell aluminium alloy foam.

\begin{tabular}{cccccc}
\hline $\mathrm{Al}$ & $\mathrm{Si}$ & $\mathrm{Cu}$ & $\mathrm{Mg}$ & $\mathrm{Mn}$ & $\mathrm{Ti}$ \\
\hline Bal. & $8.0-10.0$ & $1.3-1.8$ & $0.4-0.6$ & $0.10-0.35$ & $0.10-0.35$ \\
\hline
\end{tabular}

Ke et al. [71] performed acoustic measurements of open-cell $\mathrm{Al}$ alloy foams on its own in addition to introducing an airgap at the rear of the sample. For each of these cases, samples were tested at a pore diameter $\left(D_{\phi}\right)$ of $0.8,1.4$ and $2.2 \mathrm{~mm}$ under a constant $20 \mathrm{~mm}$ foam thickness.

From Figure 11, it is evident that when pore size increased, $\alpha$ decreased at high frequency and increased at low frequency. Furthermore, open-cell Al foam seem to have peaks of high sound absorption at high frequency $(\geq 1000 \mathrm{~Hz})$ while the frequency band remained narrow. Comparing the acoustic performance of open versus closed-cell $\mathrm{Al}$ foam; low frequency sound absorption is similar at around 0.6. However, the high frequency acoustic absorption improved with the introduction of open-cell pore structure.

The low-frequency sound absorption performance of open-cell Al foam seems to improve with the addition of an air gap. Figure 12 shows the acoustic absorption of open-cell $\mathrm{Al}$ foam at three different pore sizes featuring a rear airgap of $30 \mathrm{~mm}$. In comparison, the best performance was for the foam with the lowest pore size and worst for the highest. However, an increase in the 
half-width of the absorption peak was observed, which is similar to that of a traditional sound absorber.

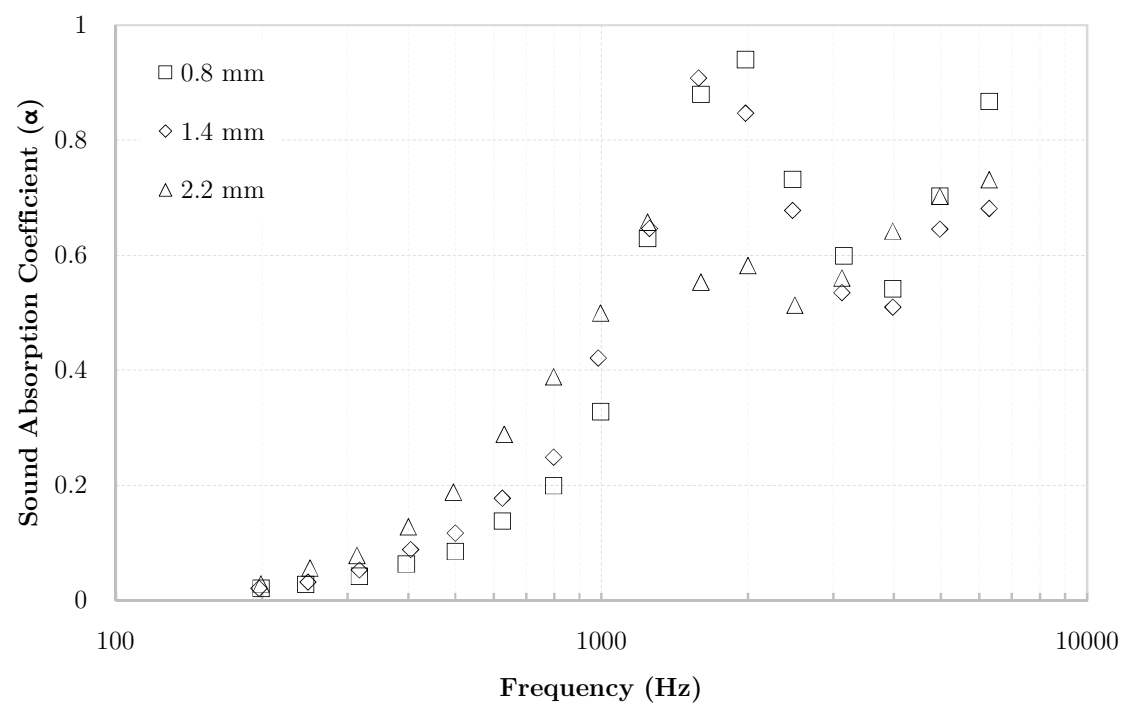

Figure 11. Influence of pore size on the sound absorption of open-cell aluminium foam featuring uniform porosity with a foam thickness of $20 \mathrm{~mm}$ [71].

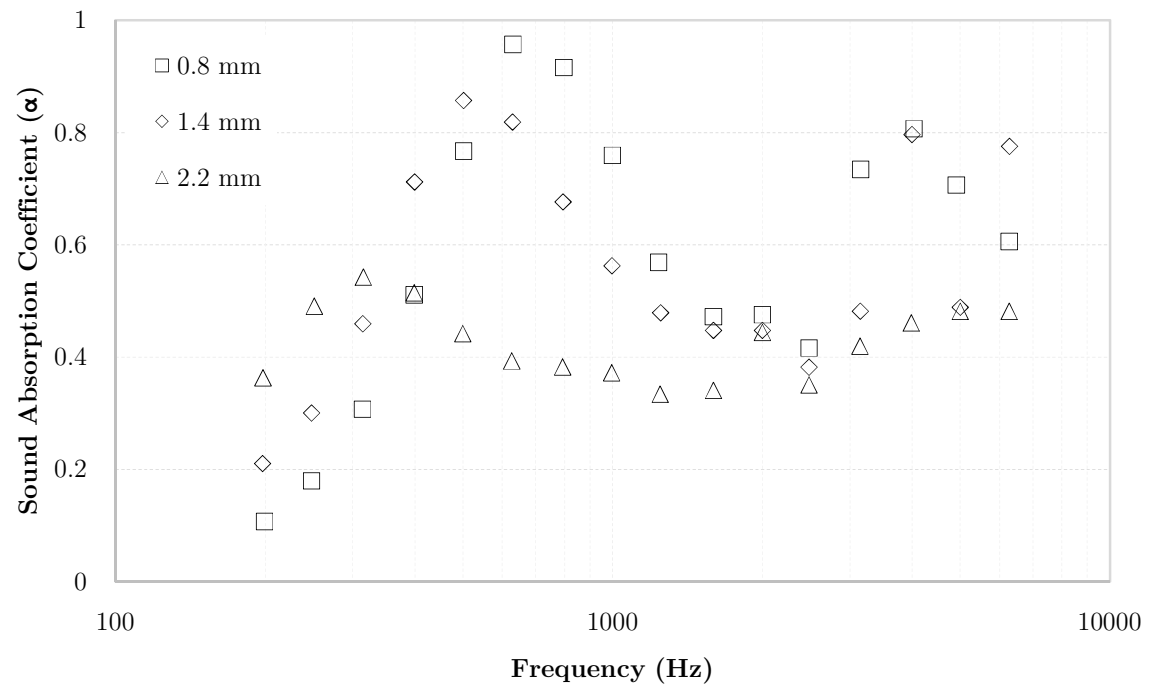

Figure 12. Influence of pore size on the sound absorption of open-cell aluminium foam featuring uniform porosity with a foam thickness of $20 \mathrm{~mm}$ with a rear airgap of $30 \mathrm{~mm}$ [71].

Overall, for open-cell Al foams, small pore size is beneficial for sound absorption at high frequencies. However, at low frequencies, the addition or air cavity is necessary to make the performance comparable to an effective sound absorber. Nevertheless, improvements are still needed as the acoustic absorption is lower than non-metallic absorbers such as glass wool. The widening of the half-width of the $\alpha$ peak in the presence of a rear cavity shows that it is a beneficial considerations on the design of open-cell metallic foam absorbers. In addition, recent 
literature [71] shows that modifications such as porosity grading may lead to improve $\alpha$ for opencell $\mathrm{Al}$ metallic foams.

\subsection{Open-cell Nickel-Inconel 625 superalloy foam}

Even though, Al foams are the highest investigated due to its wide applicability, other foams such as nickel alloys are also being experimented for its sound absorption capacity. Ni-based Inconel 625 superalloy (IN625) with typical chemical composition as shown in Table 2 are known for their high temperature and corrosion resistance in comparison to traditional $\mathrm{Al}$ foams [72].

Table 2. Chemical composition of a typical IN625 superalloy.

\begin{tabular}{cccccccc}
\hline Ni & Fe & C & Cr & Mo & Al & Ti & Nb \\
\hline Bal. & $\leq 5$ & $\leq 0.1$ & 22 & 9 & $\leq 0.4$ & $\leq 0.4$ & 3.5 \\
\hline
\end{tabular}

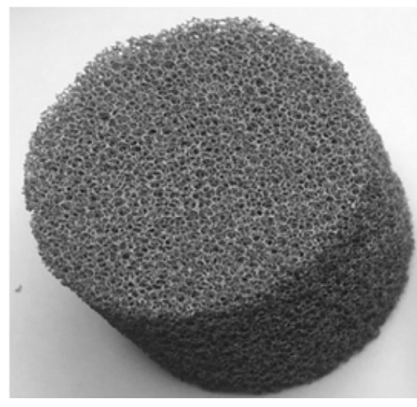

(a)

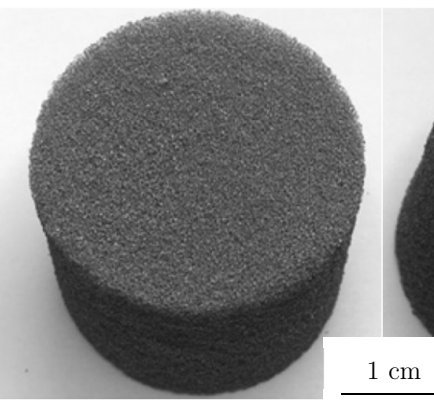

(b)

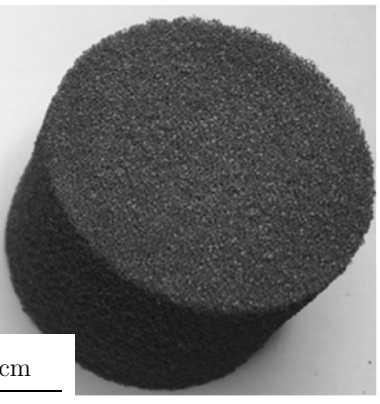

(c)

Figure 13. Typical structure of IN625 open-cell foam featuring (a) A $(\phi=98 \%)$, (b) B ( $\phi=96.5 \%)$ and (c) C ( $\phi=94.2 \%)$ [73].

Sound absorption of open cell IN625 foams exposed to high-frequency noise was carried out by Wei et al. [73]. Open-cell IN625 foam with variable porosity can be manufactured using the template replication method. Acoustic performance of IN625 foams with a typical structure shown Figure 13 are available in the literature [74,75] with associated parameters as shown in Table 3.

Table 3. Parameters of the IN625 test samples.

\begin{tabular}{cccc}
\hline Type & Porosity $(\boldsymbol{\phi}) \boldsymbol{\%}$ & Relative density $\left(\boldsymbol{\rho}_{\boldsymbol{r}}\right)$ & Thickness $\left(\boldsymbol{t}_{\boldsymbol{f o a m}}\right) \mathbf{m m}$ \\
\hline A25 and A50 & 98 & 2.0 & 25 and 50 \\
B25 and B50 & 96.5 & 3.5 & 25 and 50 \\
C25 and A50 & 94.2 & 5.8 & 25 and 50 \\
\hline
\end{tabular}

Figure 14 shows the sound absorption of a $25 \mathrm{~mm}$ thick open-cell IN625 metallic foam with associated porosity as shown in Table 3. The overall trend in the sound absorption of IN625 foam A25, B25 and C25 are similar with a gradual increase in $\alpha$ with a gradual decrease in 
porosity. While $\alpha$ of B25 were higher in comparison to A25, the overall $\alpha$ is below 0.65 , which is not representative of a good sound absorber. However, the high frequency performance of C25 exhibited $\alpha$ close to 0.7 which shows potential to be used as a sound absorber. Nevertheless, the width (frequency range where $\alpha$ is within $\pm 5 \%$ ) of the absorption curve is superior to that of $\mathrm{Al}$ and is highly representative of a good absorber.

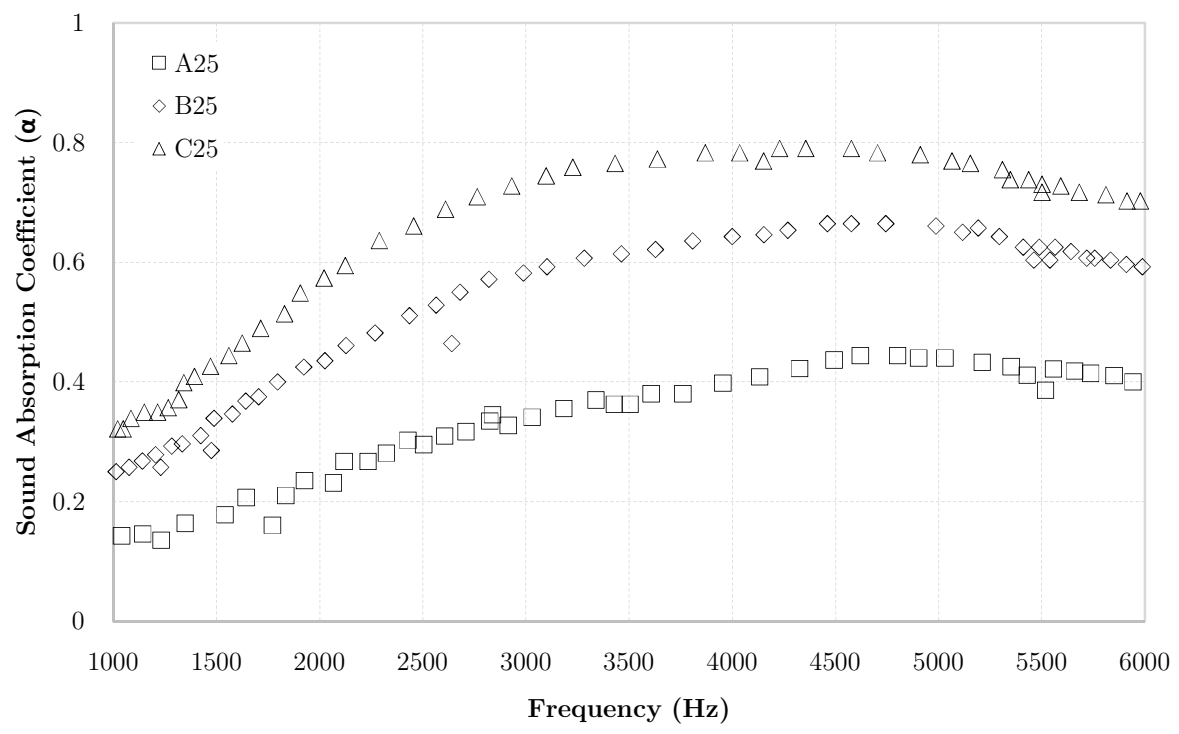

Figure 14. Influence of porosity on the sound absorption of open-cell IN625 foam with a foam thickness of $25 \mathrm{~mm}$ [73].

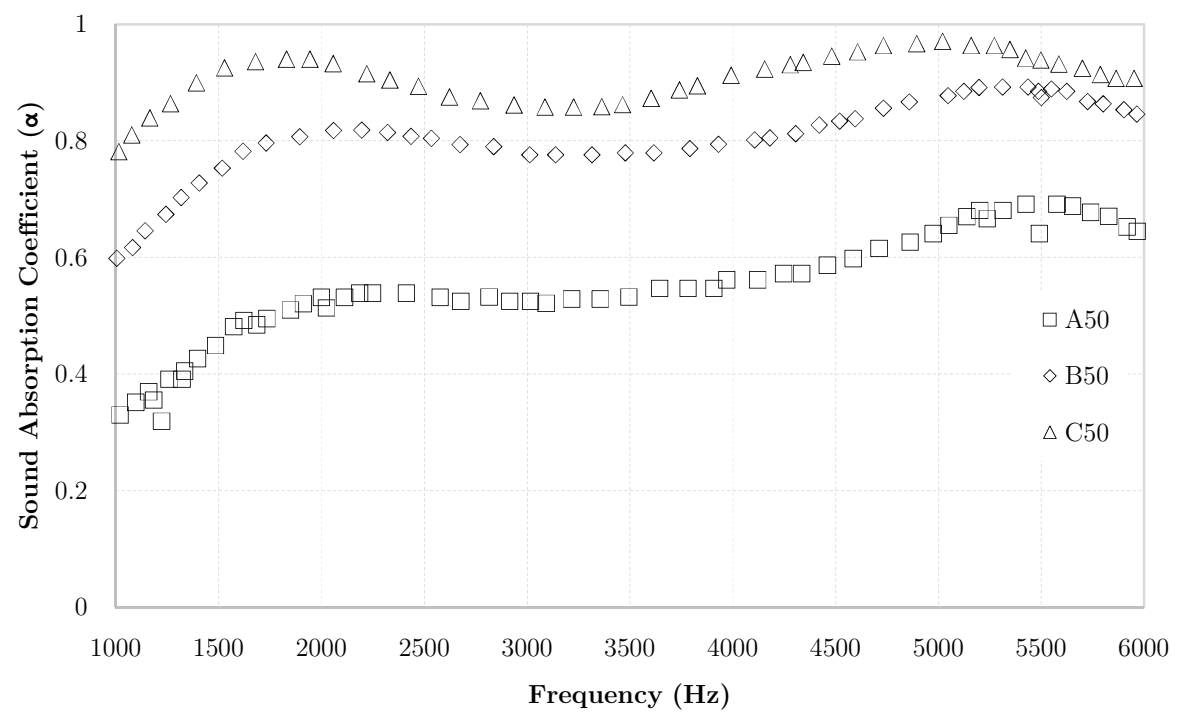

Figure 15. Influence of porosity on the sound absorption of open cell IN625 foam featuring with a thickness of $50 \mathrm{~mm}$ [73].

Additionally, the results showed that a lower porosity can lead to a higher sound absorption coefficient at high frequencies for open-cell design. When the thickness was doubled from $25 \mathrm{~mm}$ to $50 \mathrm{~mm}$ (A50, B50, and C50); $\alpha$ exhibited (Figure 15) a similar trend with the lowest porosity resulting in the highest absorption. Again, the absorption of the best performing sample C25 is 
comparable to traditional sound absorbing materials such as glass wool. Consequently ,IN625 foam with a porosity of $94.2 \%$ and a thickness of $50 \mathrm{~mm}$ can be considered a good high frequency (1000-6000 Hz) broadband sound absorber. However, the literature on the frequency performance of IN625 foams is not existent; low frequency acoustic absorption $(<1000 \mathrm{~Hz})$ is often considered most challenging when it comes to the design of broadband sound absorbers.

\subsection{Open-cell Copper foam}

Open-cell copper $(\mathrm{Cu})$ foam with a typical structure shown in Figure 16 is also being experimented as a potential sound absorbing material. The application of open-cell $\mathrm{Cu}$ foam is targeted at the noise control of large-scale equipment, such as high-powered fan, jet propulsion systems, internal-combustion engine, and heavy gas turbines [53]. This is due to the key advantages of $\mathrm{Cu}$ foams such as of high strength, good permeability, excellent fire resistance, easy processability, and long service life [25,76,77].

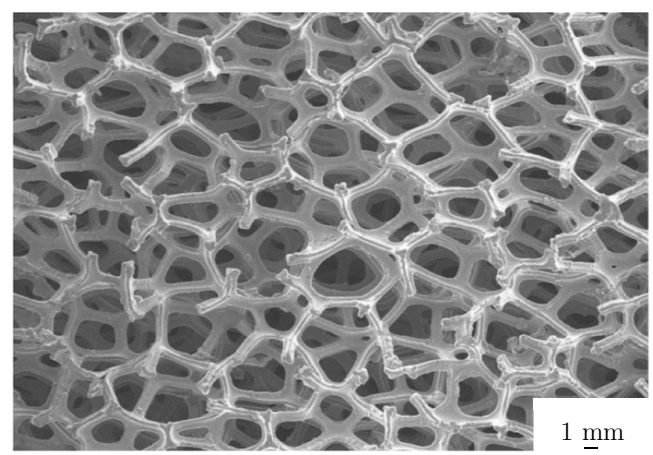

Figure 16. Typical structure of an open-cell copper foam [53].

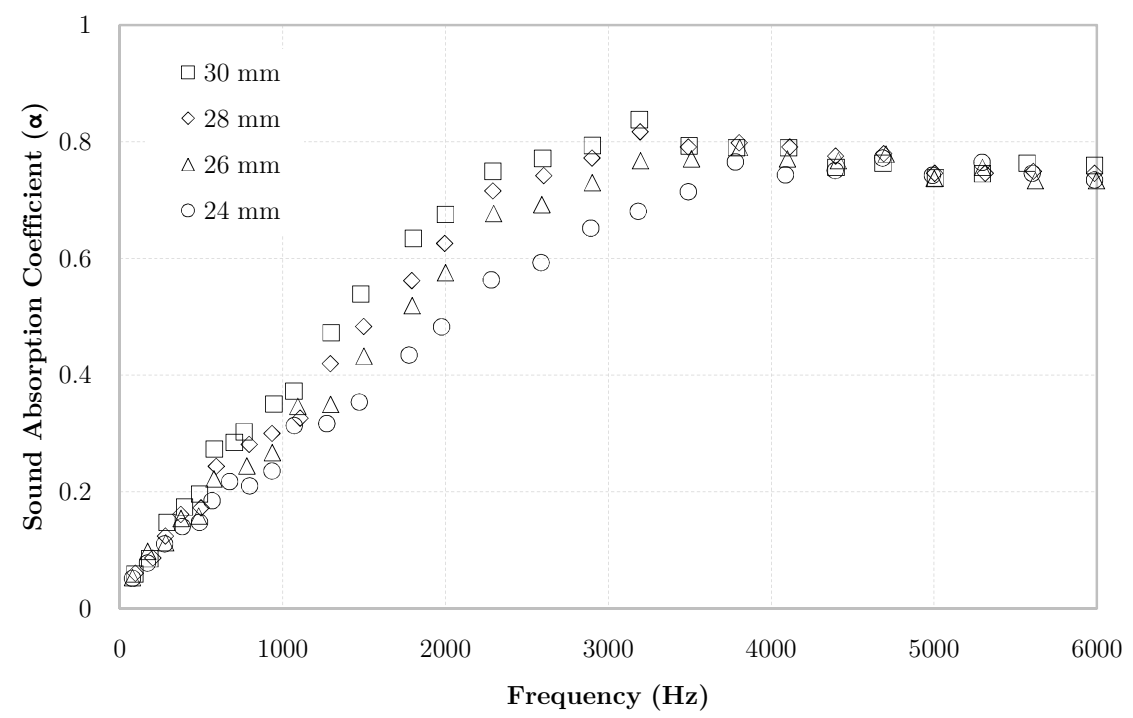

Figure 17. Influence of foam thickness on the sound absorption coefficient of open-cell copper foams [53]. 
Yang et al. [53] studied the acoustic performance of open-cell $\mathrm{Cu}$ foam under various foam thickness and rear airgap. It was found that when the thickness of an open-cell $\mathrm{Cu}$ foam increased, the sound absorption at medium frequency range (800-4000 Hz) increased as shown in Figure 17. However, at low $(\leq 800 \mathrm{~Hz})$ and high $(\geq 4000 \mathrm{~Hz})$ frequencies no significant difference was observed. Nevertheless, it can be seen that open-cell $\mathrm{Cu}$ foam have a good overall $\alpha$ considering the foam thickness.

Figure 18 shows that the acoustic absorption performance of an open-cell $\mathrm{Cu}$ foam featuring a rear airgap $\left(t_{\text {cavity }}\right)$ in addition to the foam thickness. Evaluating the performance, the overall trend in the sound absorption shows that increasing in the foam thickness is more effective in comparison to increasing the cavity thickness.

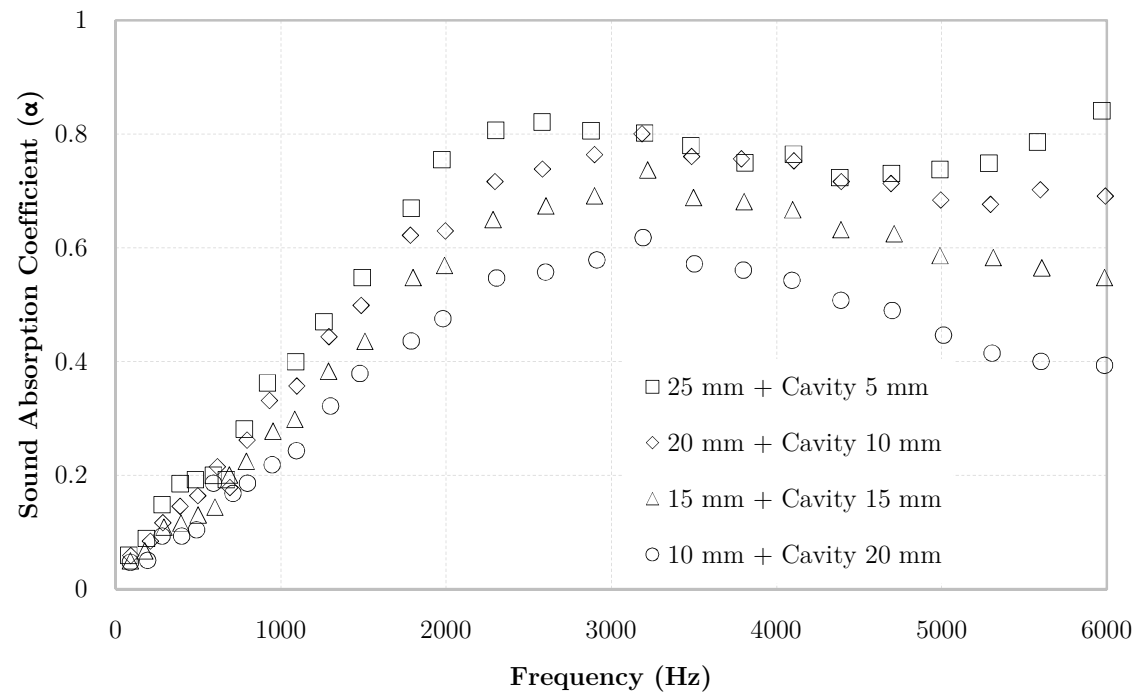

Figure 18. Influence of combined material and cavity thickness on the sound absorption of open-cell copper foams [53].

For example, a foam thickness of $25 \mathrm{~mm}$ coupled with a $5 \mathrm{~mm}$ air cavity delivers a superior $\alpha$ when compared to the sample featuring $20 \mathrm{~mm}$ material and $10 \mathrm{~mm}$ cavity. Even though the global specimen width $(30 \mathrm{~mm})$ is constant in both cases, the design featuring a higher foam thickness is superior when it comes to acoustic absorption. Nevertheless, featuring an air cavity thickness provides a valuable improvement in $\alpha$ over a design that feature no cavity given a constant material thickness.

Overall, the results showed that open-cell $\mathrm{Cu}$ copper foam can be considered good high-frequency sound absorber particularly when designed with a rear air cavity. The acoustic absorption peak along with the peak width performance at high frequency can be compared to traditional sound absorbers such as glass wool. However, further parametric investigation and optimisation are necessary to make $\mathrm{Cu}$ foams good absorbers at low to medium frequency $(<2000 \mathrm{~Hz})$. 


\section{Conclusion}

Considerable efforts are found in the literature regarding the development of both open and closed-cell metallic foams for broadband acoustic absorption with key application and acoustic advantages as shown in Table 3. Consequently, the experimental technique that can be used to characterise the sound absorption coefficient of metallic foams with an arbitrary thickness is presented. Further to this, the description of the sound absorption mechanisms in metallic foams are discussed with suitable prediction models identified and their associated parameters classified. In continuity, recent developments in metallic foams containing open and closed pores are reviewed with their acoustic absorption compared.

Compared to traditional sound absorbers, metallic foams possess structural and thermal advantage in addition to providing broadband sound absorption. However, the sound absorption in metallic foams was found to depend on numerous parameter. Closed-cell Aluminium foams possess relatively low sound absorption in comparison to its open-cell counterpart. Overall, the sound absorption of open-cell Nickel-Inconel superalloy and Copper foams seems to be the most promising when it comes to medium and high-frequency performance. When considering low frequency $(<1000 \mathrm{~Hz})$, the performance of most metallic foams seems to be inferior. However, it is acknowledged that there is a significant gap in the literature regarding the low-frequency acoustic performance of non-aluminium metallic foams.

The addition of a rear air cavity seems to be an approach pursued by many researchers to enhance the broadband sound absorption. While the influence of this approach on the amplitude of the sound absorption peaks were limited $(\leq 0.2)$, it aided in widening the frequency range of the sound absorption peaks. Consequently, it is recommended that a rear air cavity strategy be considered in the overall design of acoustic metallic foams. Nevertheless, the significance of cavity thickness in comparison to foam thickness on $\alpha$ was much smaller. This means that for a constant global thickness, a full foam thickness will be superior in comparison to 'foam plus cavity' when it comes to sound absorption. Overall, an increase in foam thickness seems to positively influence the sound absorption coefficient of open-cell metallic foams.

Regarding prediction models, the ones featuring four or more parameters seems to consider both the viscous and thermal effects within metallic foams. However, the accuracy of $\alpha$ required further correction factors to be considered for a reasonable fit with experimental data. The complexity associated with evaluating the complex parameters associated with these models also prevent them from acting as design guidelines. To this extent curve fitting models such as the Delany and Bazley still seems to be popular due to its parametric simplicity.

Despite the recent advances in the development of sound absorbing metallic foams, mass fabrication of metallic foams with controllable open pore architecture is still a challenging 
problem. Furthermore, while literature on the sound absorption of metallic foams is growing, data on other important parameters like the Sound Reduction Index or Transmission Loss are scarce.

Table 3. Application and acoustic advantages of Aluminium, Nickel-Inconel and Copper foams.

\begin{tabular}{|c|c|c|c|}
\hline Closed Cell Al & Open Cell Al & Open cell NI625 & Open cell $\mathrm{Cu}$ \\
\hline \multicolumn{4}{|c|}{ Application } \\
\hline $\begin{array}{l}\text { Wide-ranging structural } \\
\text { application due to } \\
\text { proven mechanical } \\
\text { performance and } \\
\text { machinability: Used } \\
\text { extensively in } \\
\text { Automotive, Aerospace } \\
\text { and Building application } \\
\text { for light-weighting, } \\
\text { vibration damping, } \\
\text { energy absorption, and } \\
\text { sound insulation. }\end{array}$ & $\begin{array}{l}\text { Open cell Al foam is non- } \\
\text { homogenous resulting in } \\
\text { a lower than ideal } \\
\text { repeatability in terms of } \\
\text { acoustic performance. } \\
\text { Nevertheless, they are } \\
\text { the most widely used } \\
\text { sound absorbing metallic } \\
\text { foam in Automotive, } \\
\text { Aerospace and Building } \\
\text { application. }\end{array}$ & $\begin{array}{l}\text { NI625 foams have high } \\
\text { corrosion resistance } \\
\text { compared to other } \\
\text { metallic foams in } \\
\text { addition to high tensile } \\
\text { and creep strength. } \\
\text { Sound absorption of } \\
\text { NI625 foams is a latest } \\
\text { development and their } \\
\text { application is primarily } \\
\text { focused on the Aerospace } \\
\text { industry. }\end{array}$ & $\begin{array}{l}\text { Open cell } \mathrm{Cu} \text { foams are } \\
\text { preferred for acoustic } \\
\text { absorption in high- } \\
\text { powered fan, air-jet } \\
\text { propulsion system, } \\
\text { internal-combustion } \\
\text { engine and heavy gas } \\
\text { turbine, due to their high } \\
\text { strength, good } \\
\text { permeability, excellent } \\
\text { fire resistance and high } \\
\text { heat transfer rates. }\end{array}$ \\
\hline \multicolumn{4}{|c|}{ Acoustic Performance } \\
\hline $\begin{array}{l}\text { Good for acoustic } \\
\text { insulation, but poor for } \\
\text { sound absorption. Closed } \\
\text { nature of the cells } \\
\text { prevents sound from } \\
\text { interacting with internal } \\
\text { pores. While this is good } \\
\text { for sound isolation, the } \\
\text { resulting sound } \\
\text { absorption is weak. }\end{array}$ & $\begin{array}{l}\text { Sound absorption for } \\
\text { open cell Al foams are } \\
\text { comparatively better } \\
\text { than closed cell Al. } \\
\text { However, Peak } \\
\text { absorption occurs at a } \\
\text { narrow frequency band } \\
\text { resulting in a low half } \\
\text { peak width performance. }\end{array}$ & $\begin{array}{l}\text { Sound absorption for } \\
\text { open cell NI625 foams } \\
\text { are excellent in the } \\
\text { frequency range of } 1 \text { to } 6 \\
\mathrm{kHz}(\geq 0.8) \text { at a foam } \\
\text { thickness of } 50 \mathrm{~mm} \text {. Peak } \\
\text { absorption occurs over a } \\
\text { wide frequency resulting } \\
\text { in broadband sound } \\
\text { absorption. }\end{array}$ & $\begin{array}{l}\text { Sound absorption for } \\
\text { open cell Cu foams are } \\
\text { good in the frequency } \\
\text { range of } 2 \text { to } 6 \mathrm{kHz} \\
(\geq 0.7) \text { at a foam } \\
\text { thickness of } 30 \mathrm{~mm} \text {. Peak } \\
\text { absorption occurs over a } \\
\text { relatively wide frequency } \\
\text { band. }\end{array}$ \\
\hline \multicolumn{4}{|c|}{ Environment } \\
\hline $\begin{array}{l}\text { Suitable for sound } \\
\text { insulation (not } \\
\text { absorption) in low to } \\
\text { moderate temperature } \\
\text { application, where high } \\
\text { thermal dissipation } \\
(\leq 235 \mathrm{~W} / \mathrm{m} \cdot \mathrm{K}) \text { is } \\
\text { required. }\end{array}$ & $\begin{array}{l}\text { Suitable for sound } \\
\text { absorption in low to } \\
\text { moderate temperature } \\
\text { application where high } \\
\text { thermal dissipation } \\
(\leq 235 \mathrm{~W} / \mathrm{m} \cdot \mathrm{K}) \text { is } \\
\text { required. }\end{array}$ & $\begin{array}{l}\text { Suitable for sound } \\
\text { absorption in high- } \\
\text { temperature application } \\
\text { where low thermal } \\
\text { dissipation }(\leq 9.8 \\
\mathrm{W} / \mathrm{m} \cdot \mathrm{K}) \text { and high } \\
\text { thermal resistance is } \\
\text { required. }\end{array}$ & $\begin{array}{l}\text { Suitable for sound } \\
\text { absorption in high- } \\
\text { temperature application } \\
\text { where high thermal } \\
\text { dissipation }(\leq 360 \\
\mathrm{W} / \mathrm{m} \cdot \mathrm{K}) \text {. is required. }\end{array}$ \\
\hline \multicolumn{4}{|c|}{ Strategies for improving sound absorption coefficient } \\
\hline $\begin{array}{l}\text { Opening the pore } \\
\text { structure through } \\
\text { compression, drilling, } \\
\text { milling or sandblasting. }\end{array}$ & \multicolumn{3}{|c|}{$\begin{array}{l}\text { The use of rear airgap can increase both the absorption peak and half peak width } \\
\text { in open-cell metallic foams. }\end{array}$} \\
\hline \multicolumn{4}{|c|}{ Manufacturing } \\
\hline $\begin{array}{l}\text { Manufactured through } \\
\text { gas bubbling or direct } \\
\text { mixing of foaming agent } \\
\text { into the molten metal. } \\
\text { The process is relatively } \\
\text { easy and economical. }\end{array}$ & \multicolumn{3}{|c|}{$\begin{array}{l}\text { Open cell foams are manufactured through casting, powder metallurgy or additive } \\
\text { manufacturing. In the powder method, space holders are used for the required } \\
\text { pore geometry. When it comes to casting, a polyurethane skeleton is the widely } \\
\text { applied choice. Additively manufactured open cell foams generally use the Direct } \\
\text { Metal Laser Sintering (DMLS) method. }\end{array}$} \\
\hline
\end{tabular}




\section{References}

[1] Baroutaji A, Gilchrist MD, Smyth D, Olabi AG. Analysis and optimization of sandwich tubes energy absorbers under lateral loading. Int J Impact Eng 2015;82:74-88.

[2] Baroutaji A, Sajjia M, Olabi A. Metallic Thin-Walled Tubes for Crashworthiness Applications: A Reference Guide. 2017.

[3] Baroutaji A, Sajjia M, Olabi A-. On the crashworthiness performance of thin-walled energy absorbers: Recent advances and future developments. Thin-Walled Struct 2017;118:137-63.

[4] Arjunan A, Wang C, English M, Stanford M, Lister P. A Computationally-Efficient Numerical Model to Characterize the Noise Behavior of Metal-Framed Walls. Metals 2015;5:1414.

[5] Arjunan A, Wang CJ, Yahiaoui K, Mynors DJ, Morgan T, Nguyen VB et al. Development of a 3D finite element acoustic model to predict the sound reduction index of stud based double-leaf walls. J Sound Vib 2014;333:6140-55.

[6] Arjunan A, Wang CJ, Yahiaoui K, Mynors DJ, Morgan T, English M. Finite element acoustic analysis of a steel stud based double-leaf wall. Build Environ 2013;67:202-10.

[7] Arjunan A, Rackley J, Stanford M. Experimental investigation on the sound reduction performance of frequency controlled acoustic interference cavities. Proc INTER-NOISE - Int Congr Expo Noise Control Eng : Towar Quieter Future 2016:4211-9.

[8] Arjunan A. Sound transmission loss of light-weight slotted steel studs in a gypsum plasterboard partition wall. Proc INTER-NOISE - Int Congr Expo Noise Control Eng : Towar Quieter Future 2016:99-110.

[9] Rousounelos A, Walsh SJ, Krylov VV, Horner JL. Optimisation of the structural modes of automotive-type panels using line stiffeners and point masses to achieve weak acoustic radiation. Applied Acoustics 2015;93:23-37.

[10] Lu Y, Wang F, Ma X. Helicopter interior noise reduction using compounded periodic struts. Journal of Sound and Vibration 2018;435:264-80.

[11] Perrot C, Chevillotte F, Jaouen L, Hoang M. Acoustics properties and applications, in Metallic Foams: Fundamentals and Applications., 2013.

[12] Otaru AJ. Enhancing the sound absorption performance of porous metals using tomography images. Applied Acoustics 2019;143:183-9.

[13] Devivier C, Tagliaferri V, Trovalusci F, Ucciardello N. Mechanical characterization of open cell aluminium foams reinforced by nickel electro-deposition. Materials \& Design 2015;86:272-8.

[14] LIU P, XU X, CHENG W, CHEN J. Sound absorption of several various nickel foam multilayer structures at aural frequencies sensitive for human ears. Transactions of Nonferrous Metals Society of China 2018;28:1334-41. 
[15] CHENG W, DUAN C-, LIU P-, LU M. Sound absorption performance of various nickel foam-base multi-layer structures in range of low frequency. Trans Nonferrous Met Soc China 2017;27:1989-95.

[16] Xiao X, Zhang P, Li M. Preparation and thermal characterization of paraffin/metal foam composite phase change material. Applied Energy 2013;112:1357-66.

[17] Lu TJ, Hess A, Ashby MF. Sound absorption in metallic foams. J Appl Phys 1999;85:7528-39.

[18] Qiu X. Principles of Sound Absorbers. 2016:43-72.

[19] Chen D, Hou L, Zhou W, Liu R. Tri-dimensional reticulated porous material sintered by multitooth tool cutting-made copper fibers and investigation of its acoustical performances. Mater Lett 2017;194:9-12.

[20] Johnson DL, Koplik J, Dashen R. Theory of dynamic permeability and tortuosity in fluid saturated porous media. J Fluid Mech 1987;176:379-402.

[21] Chen S, Jiang Y, Chen J, Wang D. The Effects of Various Additive Components on the Sound Absorption Performances of Polyurethane Foams. Adv Mater Sci Eng 2015;2015.

[22] Quadbeck P, Kaschta J, Singer RF. Superalloy IN625 with cellular microstructure - Fabrication route and mechanical properties. Adv Eng Mater 2004;6:635,639+610.

[23] CHENG W, DUAN C-, LIU P-, LU M. Sound absorption performance of various nickel foam-base multi-layer structures in range of low frequency. Trans Nonferrous Met Soc China 2017;27:1989-95.

[24] Lu TJ, Chen F, He D. Sound absorption of cellular metals with semiopen cells. J Acoust Soc Am 2000;108:1697-709.

[25] Xie Z, Ikeda T, Okuda Y, Nakajima H. Sound absorption characteristics of lotus-type porous copper fabricated by unidirectional solidification. Mater Sci Eng A 2004;386:390-5.

[26] Cuiyun D, Guang C, Xinbang X, Peisheng L. Sound absorption characteristics of a hightemperature sintering porous ceramic material. Appl Acoust 2012;73:865-71.

[27] Azizan MA, Ismail MH, Salleh NAM, Natarajan DV. Sound absorption properties at high sound frequency of open cell aluminium foam. J Mech Eng 2017;SI 2:161-73.

[28] Liang L, Zhang X, Song Y, Lu M, Luo S, Ji Z. Advances of sound absorption feature of aluminum foams. Cailiao Daobao/Mater Rev 2016;30:64-71.

[29] Liang L, Wu X, Ma N, Du J, Liu M. The sound absorption properties comparison of metal foams and flexible cellular materials. Mater Sci Forum 2018;933 MSF:357-66.

[30] Wang W, Liu H, Gu W. A novel fabrication approach for improving the mechanical and sound absorbing properties of porous sound-absorbing ceramics. J Alloys Compd 2017;695:2477-82. 
[31] Kim SK, Sung G, Gwon JG, Kim JH. Controlled phase separation in flexible polyurethane foams with diethanolamine cross-linker for improved sound absorption efficiency. Int J Precis Eng Manuf Green Technol 2016;3:367-73.

[32] Yang XH, Ren SW, Wang WB, Liu X, Xin FX, Lu TJ. A simplistic unit cell model for sound absorption of cellular foams with fully/semi-open cells. Compos Sci Technol 2015;118:276-83.

[33] Itoh M, Nishikawa T. J.Met.Soc.Jpn. 1987;26:311.

[34] Lu TJ, Chen F, He D. Sound absorption of cellular metals with semiopen cells. J Acoust Soc Am 2000;108:1697-709.

[35] Han F, Seiffert G, Zhao Y, Gibbs B. Acoustic absorption behaviour of an open-celled aluminium foam. J Phys D 2003;36:294-302.

[36] Crocker MJ. Handbook of Acoustics. : Wiley, 1998.

[37] Larner DJ, Davy JL. The prediction of the complex characteristic acoustic impedance of porous materials. INTERNOISE - Int Congr Noise Control Eng : Improv World Through Noise Control 2014.

[38] Dupont T, Leclaire P, Panneton R, Umnova O. A microstructure material design for low frequency sound absorption. Applied Acoustics 2018;136:86-93.

[39] Lu T, Kepets M, Dowling AP. Acoustic properties of sintered FeCrAlY foams with open cells (I): Static flow resistance. Sci China Ser E Technol Sci 2008;51:1803-11.

[40] Zwikker C, Kosten CW. Sound Absorbing Materials 1949.

[41] Utsuno H, Seybert AF. Transfer function method for measuring characteristic impedance and propagation constant of porous materials. J Acoust Soc Am 1989;86:637-43.

[42] Peng L. 13 - Sound absorption and insulation functional composites. 2017:333-73.

[43] Champoux Y, Allard J-. Dynamic tortuosity and bulk modulus in air-saturated porous media. J Appl Phys 1991;70:1975-9.

[44] Cao L, Fu Q, Si Y, Ding B, Yu J. Porous materials for sound absorption. Composites Communications 2018;10:25-35.

[45] Rahimabady M, Statharas EC, Yao K, Sharifzadeh Mirshekarloo M, Chen S, Tay FEH. Hybrid local piezoelectric and conductive functions for high performance airborne sound absorption. Appl Phys Lett $2017 ; 111$.

[46] Peng L, Song B, Wang J, Wang D. Mechanic and acoustic properties of the sound-absorbing material made from natural fiber and polyester. Adv Mater Sci Eng 2015;2015.

[47] Mati-Baouche N, de Baynast H, Michaud P, Dupont T, Leclaire P. Sound absorption properties of a sunflower composite made from crushed stem particles and from chitosan bio-binder. Applied Acoustics 2016;111:179-87. 
[48] Oliva D, Hongisto V. Sound absorption of porous materials - Accuracy of prediction methods. Appl Acoust 2013;74:1473-9.

[49] Delany ME, Bazley EN. Acoustical properties of fibrous absorbent materials. Appl Acoust 1970;3:105-16.

[50] Miki Y. Acoustical properties of porous materials :-Generalizations of empirical models-. J Acoust Soc Jpn 1990;11:25-8.

[51] Komatsu T. Improvement of the Delany-Bazley and Miki models for fibrous sound-absorbing materials. Acoust Sci Technol 2008;29:121-9.

[52] Zhai W, Yu X, Song X, Ang LYL, Cui F, Lee HP et al. Microstructure-based experimental and numerical investigations on the sound absorption property of open-cell metallic foams manufactured by a template replication technique. Mater Des 2018;137:108-16.

[53] Yang X, Peng K, Shen X, Zhang X, Bai P, Xu P. Geometrical and Dimensional Optimization of Sound Absorbing Porous Copper with Cavity. Mater Des 2017;131:297-306.

[54] Meriç C, Erol H, Özkan A. On the sound absorption performance of a felt sound absorber. Appl Acoust 2016;114:275-80.

[55] Chevillotte F, Perrot C. Effect of the three-dimensional microstructure on the sound absorption of foams: A parametric study. J Acoust Soc Am 2017;142:1130-40.

[56] Ren S, Xin F, Lu TJ, Zhang C. A semi-analytical model for the influence of temperature on sound propagation in sintered metal fiber materials. Mater Des 2017;134:513-22.

[57] Leclaire P. Characterization of porous absorbent materials. 2012.

[58] Wilson DK, Ostashev VE, Collier SL. Time-domain equations for sound propagation in rigid-frame porous media (L). J Acoust Soc Am 2004;116:1889-92.

[59] Banhart J. Manufacture, characterisation and application of cellular metals and metal foams. Prog Mat Sci 2001;46:559-632.

[60] Li Z, Huang Y, Wang X, Wang X, Wang D, Han F. Enhancement of open cell aluminum foams through thermal evaporating Zn film. Mater Lett 2016;172:120-4.

[61] Navacerrada MA, Fernández P, Díaz C, Pedrero A. Thermal and acoustic properties of aluminium foams manufactured by the infiltration process. Appl Acoust 2013;74:496-501.

[62] Stephani G, Scheffler M. Proceedings to the Conference on Cellular Materials - CELLMAT 2012, Dresden, Germany 2012.

[63] Arjunan A. Sound Transmission Loss of Light-Weight Slotted Steel Studs in a Gypsum Plasterboard Partition Wall. INTER-NOISE 2016 (ISSN 0105-175x) 2016. 
[64] BS EN ISO 10140-1: Acoustics. Laboratory Measurement of Sound Insulation of Building Elements. Application Rules for Specific Products. 2014.

[65] Miyoshi T, Itoh M, Akiyama S, Kitahara A. Aluminum foam, 'ALPORAS': the production process, properties and applications. Mater Res Soc Symp Proc 1998;521:133-7.

[66] Miyoshi T, Itoh M, Akiyama S, Kitahara A. ALPORAS aluminum foam: Production process, properties, and applications. Adv Eng Mater 2000;2:179-83.

[67] Wang X, Lu TJ. Optimized acoustic properties of cellular solids. J Acoust Soc Am 1999;106:756-65.

[68] Han F, Seiffert G, Zhao Y, Gibbs B. Acoustic absorption behaviour of an open-celled aluminium foam. J Phys D 2003;36:294-302.

[69] Li YJ, Li ZD, Han FS. Procedia Mater.Sci. 2014;4:180-3.

[70] ERG Materials and Aerospace. Aluminium Duocel Foam Material. 2018;2018.

[71] Huang K, Yang D, He S, He D. Acoustic absorption properties of open-cell Al alloy foams with graded pore size. J Phys D 2011;44.

[72] Zhang Q, Chang Y, Gu L, Luo Y, Ge B. Study of microstructure of nickel-based superalloys at high temperatures. Scripta Mater 2017;126:55-7.

[73] Zhai W, Yu X, Song X, Ang LYL, Cui F, Lee HP et al. Microstructure-based experimental and numerical investigations on the sound absorption property of open-cell metallic foams manufactured by a template replication technique. Mater Des 2018;137:108-16.

[74] YU X, ZHAI W, SONG X, CUI F. Numerical and Experimental Study on the Acoustic Performance of Ni-based Superalloy Open Cell Foam. Procedia Engineering 2017;214:4-8.

[75] Zhai W, Yu X, Song X, Ang LYL, Cui F, Lee HP et al. Microstructure-based experimental and numerical investigations on the sound absorption property of open-cell metallic foams manufactured by a template replication technique. Materials \& Design 2018;137:108-16.

[76] Ru J, Kong B, Liu Y, Wang X, Fan T, Zhang D. Microstructure and sound absorption of porous copper prepared by resin curing and foaming method. Mater Lett 2015;139:318-21.

[77] Hyun SK, Nakajima H. Anisotropic compressive properties of porous copper produced by unidirectional solidification. Mater Sci Eng A 2003;340:258-64. 